\title{
Marker assisted pyramiding of two brown planthopper resistance genes, Bph3 and Bph27 (t), into elite rice Cultivars
}

Yanling Liu ${ }^{1 \dagger}$, Liangming Chen ${ }^{1 \dagger}$, Yuqiang Liu ${ }^{1 \dagger}$, Huimin Dai ${ }^{1}$, Jun He ${ }^{1}$, Haiyan Kang ${ }^{1}$, Gen Pan ${ }^{1}$, Jie Huang ${ }^{1}$, Zeyu Qiu', Qi Wang ${ }^{1}$, Jinlong Hư ${ }^{1}$, Linglong Liư ${ }^{1}$, Yezhi Chen ${ }^{1}$, Xianian Cheng ${ }^{1}$, Ling Jiang ${ }^{1}$ and Jianmin Wan ${ }^{1,2^{*}}$

\begin{abstract}
Background: Brown planthopper (BPH) is the most destructive insect in rice production. Breeding of resistant cultivars is the most cost-effective and environment-friendly strategy for BPH management; however, resistant cultivars are currently hampered by the rapid breakdown of BPH resistance. Thus, there is an urgent need to use more effective BPH resistance genes or pyramiding different resistance genes to develop more durable resistant rice cultivars.

Results: Here a dominant BPH resistance gene $B p h 27(t)$ were introgressed into a susceptible commercial japonica variety Ningjing3 (NJ3) and indica variety 93-11 using marker-assisted selection (MAS), respectively. Further, Bph27(t) and a durable BPH resistance gene Bph3 was pyramided by intercrossing single-gene introgressed lines through MAS. The introgression of $\mathrm{BPH}$ resistance genes significantly improved the BPH resistance and reduced the yield loss caused by BPH.
\end{abstract}

Conclusion: The development of single and two genes pyramided lines in this study provides innovative resources for molecular breeding of durable BPH-resistant rice cultivars and BPH management through resistant cultivars.

Keywords: Marker-Assisted selection (MAS), Pyramiding breeding, Brown planthopper, Rice

\section{Background}

Rice is a staple food for over half of world population, while serious yield loss was caused by diseases and insects attack annually (Akhtar et al. 2010; Zhai 2011; Hu et al. 2014). Brown planthopper (BPH) has become a major destructive insect and caused seriously loss in rice production (Way and Heong 1994; Heinrichs and Mochida 1984). Nowadays, pesticide abuse in $\mathrm{BPH}$ management has heavily polluted the environment and resulted in the tolerance of BPH to the insecticides (Tanaka et al. 2000). Development of resistant rice cultivars is considered the most economic effective and environment-friendly measure for controlling this insect.

In response to the serious damage caused by $\mathrm{BPH}$, resistance varieties were developed sequentially based on

\footnotetext{
*Correspondence: wanjm@njau.edu.cn; wanjianmin@caas.cn

${ }^{\dagger}$ Equal contributors

${ }^{1}$ National Key Laboratory of Crop Genetics and Germplasm Enhancement, Nanjing Agricultural University, Nanjing 210095, People's Republic of China ${ }^{2}$ Chinese Academy of Agricultural Sciences, Beijing 100081, People's Republic of China
}

the identification of some $\mathrm{BPH}$ resistance genes (Suh et al. 2011). However, some of the varieties bearing the $\mathrm{BPH}$ resistance genes were quickly broken down within a few years due to rapid adaptation of BPH (Khush 1977). Resistant varieties with Bph1 were initially released in 1973, but these varieties were already adapted and overcome by BPH in 1975 (Cohen et al. 1997). Then some varieties with the $b p h 2$ derived from ASD7 were released, but again, in the early 1980s, these varieties were also adapted by BPH. Since 1982, some varieties with resistance gene Bph3 have been released (Khush and Virk 2005). Bph3 display broad spectrum resistance to all four BPH biotypes. In contrast with $B p h 1$ and $b p h 2$, though the varieties harboring Bph3 have been deployed over 30 years in the Philippines, they still retain effect against BPH (Cruz et al. 2011). Thus, Bph3 has great potential in developing broad spectrum and durable resistant varieties against $\mathrm{BPH}$. Recently, Bph3 from Rathu Heenati (RH) has been successfully cloned, which proved that the Bph3 resistance 
is conferred by a cluster of three plasma membranelocalized lectin receptor kinases (Liu et al. 2015).

In addition to application of durable resistance genes, pyramiding multiple $\mathrm{BPH}$ resistance genes is another efficient strategy to develop durable resistant varieties against $\mathrm{BPH}$. Previously the $\mathrm{BPH}$ resistance cultivars were mainly bred by traditional breeding approach, which generally led to time- and labor-consuming and low efficiency, especially for pyramiding multiple genes. Molecular marker-assisted selection (MAS) is considered as an efficient and rapid approach for introducing and pyramiding BPH resistance genes (Qiu et al. 2010). Molecular mapping would facilitate the MAS for providing the resistance genes (Huang et al. 2013; Jena and Kim 2010). So far, $29 \mathrm{BPH}$ resistance genes have been identified from cultivated and wild rice (Cheng et al. 2013; $\mathrm{Wu}$ et al. 2014). Among them, previous studies demonstrated that three varieties Balamawee $(\mathrm{Ba})$, Kaharamana and Pokkali might carry the same BPH resistance gene, designed as Bph9 (Nemoto et al. 1989). Subsequently, Murata et al. and Su et al. located Bph9 on the long arm of rice chromosome 12 using Pokkali and Kaharamana, respectively (Murata et al. 2000; Su 2006). However, comparing various characteristics of $\mathrm{BPH}$ behavior found that the feeding behavior of $\mathrm{BPH}$ on $\mathrm{Ba}$ was significantly different from that on the other two cultivars. The resistance gene in $\mathrm{Ba}$ was then finely mapped on chromosome 4 and named as Bph27(t) (He et al. 2013).

In present study, we introgressed $B p h 27(t)$ into susceptible commercial japonica variety Ningjing3 (NJ3) and indica variety 93-11 using marker-assisted selection (MAS), respectively. The introgression of $B p h 27(t)$ significantly improved the BPH resistance level and reduced the yield loss caused by BPH. Further, we pyramided Bph3 and $B p h 27(t)$ by intercrossing Bph3 and Bph27(t) single gene introgressed japonica lines through MAS. The development of BPH resistance lines with single and two genes pyramided have a promising future in molecular breeding of durable BPH-resistant rice cultivars.

\section{Results}

Introgression of $B p h 27(t)$ into japonica and indica cultivar rice Ningjing3 (NJ3) is one of the most widely cultured elite japonica varieties in Jiangsu Providence, China, but it showed highly susceptible to BPH. In order to develop BPH resistant Japonica cultivars, NJ3 was used as the recurrent parent to backcross with $\mathrm{Ba}$ for six generations and then self-crossed to produce a $\mathrm{BC}_{6} \mathrm{~F}_{2}$ population. Two markers (Q52 and Q31) reported by $\mathrm{He}$ et al. (2013) were used for tracking introgression of Bph27(t) (Table 1). To introgress Bph27(t) into indica cultivar 93-11, the same procedure as described above was conducted, except that markers were replaced by RM471 and Q58 (Table 1). Finally, a Bph27(t)-carrying japonica line R2256 and indica line R3-166 were selected from the $\mathrm{BC}_{6} \mathrm{~F}_{2}$ populations (Fig. 1).

A total of 321 and 218 evenly distributed and polymorphic markers were used to identify the background of the introgression lines R2256 and R3-166, respectively. The results showed that NJ3 background of R2256 have arrived at $97.7 \%$ (Fig. 1c, e), and 93-11 background of R3166 also have arrived at $99.5 \%$ (Fig. 1f). Therefore, these results demonstrated that $B p h 27(t)$ have been successfully introduced into NJ3 and 93-11 through MAS.

\section{Evaluation of BPH resistance and other agronomic traits of introgression lines}

To test whether the introgression of $B p h 27(t)$ can improve the BPH resistance of NJ3 and 93-11, we evaluated the $\mathrm{BPH}$ resistance of these introgression lines at the seedling stage under greenhouse conditions. While the recurrent parent NJ3 and 93-11 were completely dead, $B p h 27(t)$-carrying lines R2256 and R3-152 showed no visible damage (Fig. 1). The BPH resistance evaluation was also conducted under artificial infestation conditions in the field at mature stage. The results showed that two introgression lines of $B p h 27(t)$ also displayed high resistance against $\mathrm{BPH}$ the same as that of Bph3-introgressing line R2381 at mature stage in the field (Fig. 2).

To evaluate the resistance level of heterozygous $B p h 27(t)$ and potential application in hybrid rice breeding, R2381 and R2256 were separately backcrossed with NJ3 and intercrossed simultaneously. When the NJ3 plants nearly completely died, R2381/NJ3 $F_{1}$, R2256/NJ3 $\mathrm{F}_{1}$ and R2381/R2256 $\mathrm{F}_{1}$ showed invisible damaged symptom (Fig. 3a, b). Similarly to Bph3, the results showed that $B p h 27(t)$ also is a dominant gene for $\mathrm{BPH}$ resistance.

Table 1 Markers used for Bph3 and Bph27(t) marker-assisted selection in this study

\begin{tabular}{lll}
\hline Mark name & Forward primer ( ( $\left.^{\prime}-3^{\prime}\right)$ & Reverse primer $\left(5^{\prime}-3^{\prime}\right)$ \\
\hline RH078 & GTAAAAAGTTGGATTGGC & GGCGAGTTGTGCTGTTG \\
RH7 & CAGGTTGGTTGAGGGTCT & GAACTATGGCTCCACTGGTCTA \\
Q52 & GCAAAGTACAAAACTAGCACA & TCAGTAAACTCACGAATAAAGC \\
Q31 & GTTCCCTCATACGGATAG & AGATTGACAAGGCTTACT \\
Q58 & CATGCTGAGACCAAATTACTACA & GGGGTGGGCAAAATAAGA \\
RM471 & ACGCACAAGCAGATGATGAG & GGGAGAAGACGAATGTTGC \\
\hline
\end{tabular}



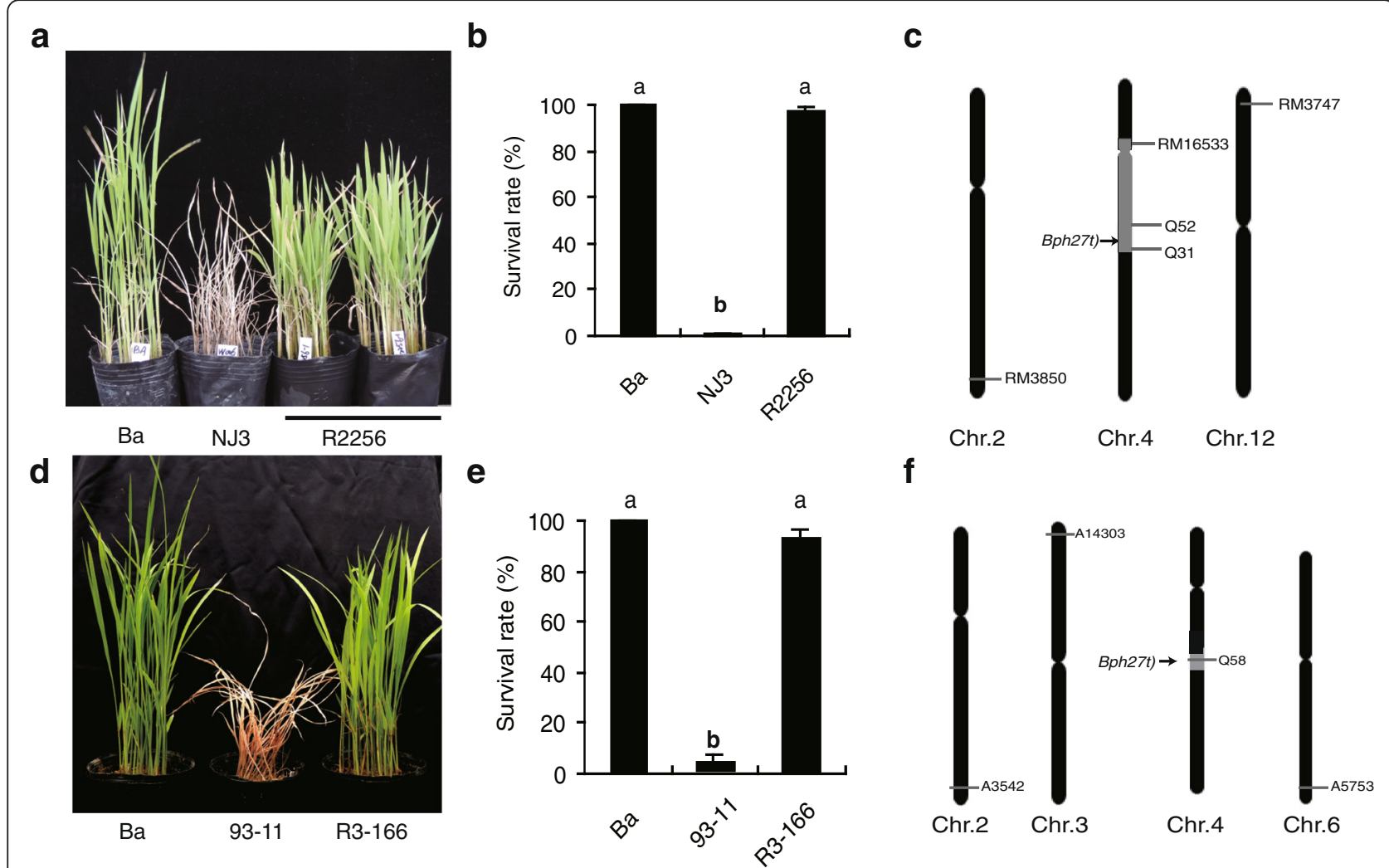

Fig. 1 Improvement of BPH resistance by introgression of $B p h 27(t)$ into japonica (a-c) and indica rice cultivars (d-f), respectively. Letters indicate a significant difference at $P<0.01$ by the Student's $t$-test ( $\mathbf{b}$ and $\mathbf{e}$ ). A diagram ( $\mathbf{c}$ and $\mathbf{d}$ ) showing the chromosomal contribution of Ba (gray) and Ningjing 3 or $93-11$ (black)
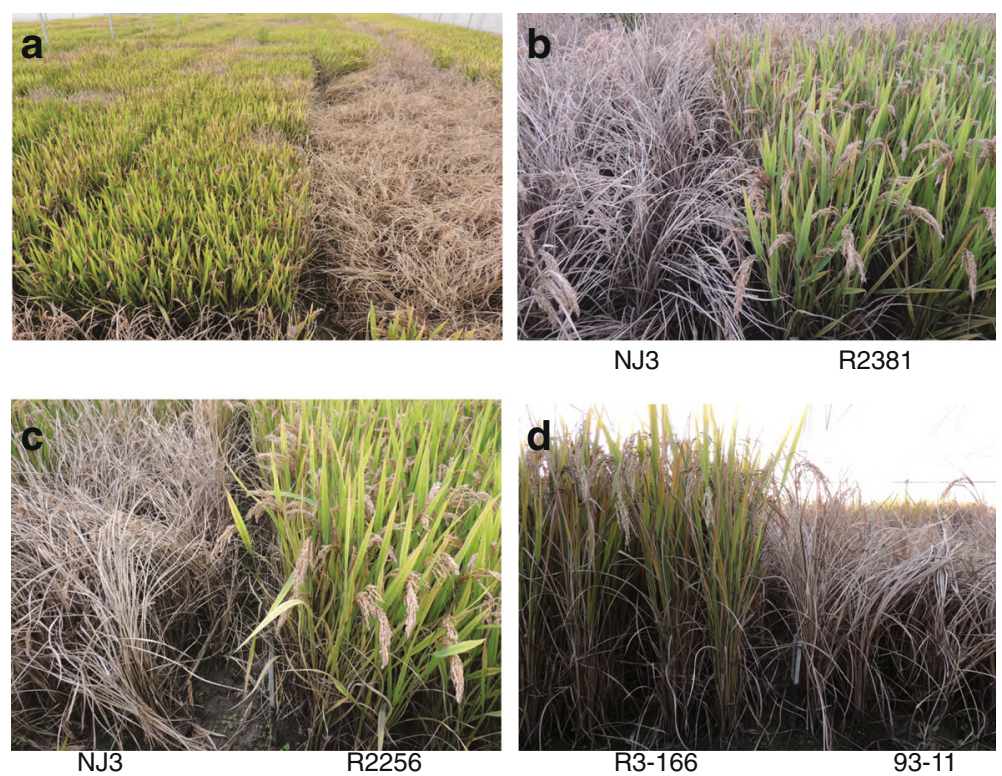

Fig. $2 \mathrm{BPH}$ resistance of $B p h 27(t)$-containing introgression lines at mature stage in the field. a Overall view of the BPH resistance at mature stage; b Bph3-containing japonica near-isogenic line R2381; c, d Bph27-containing japonica and indica near-isogenic line R22256 and R3-166 

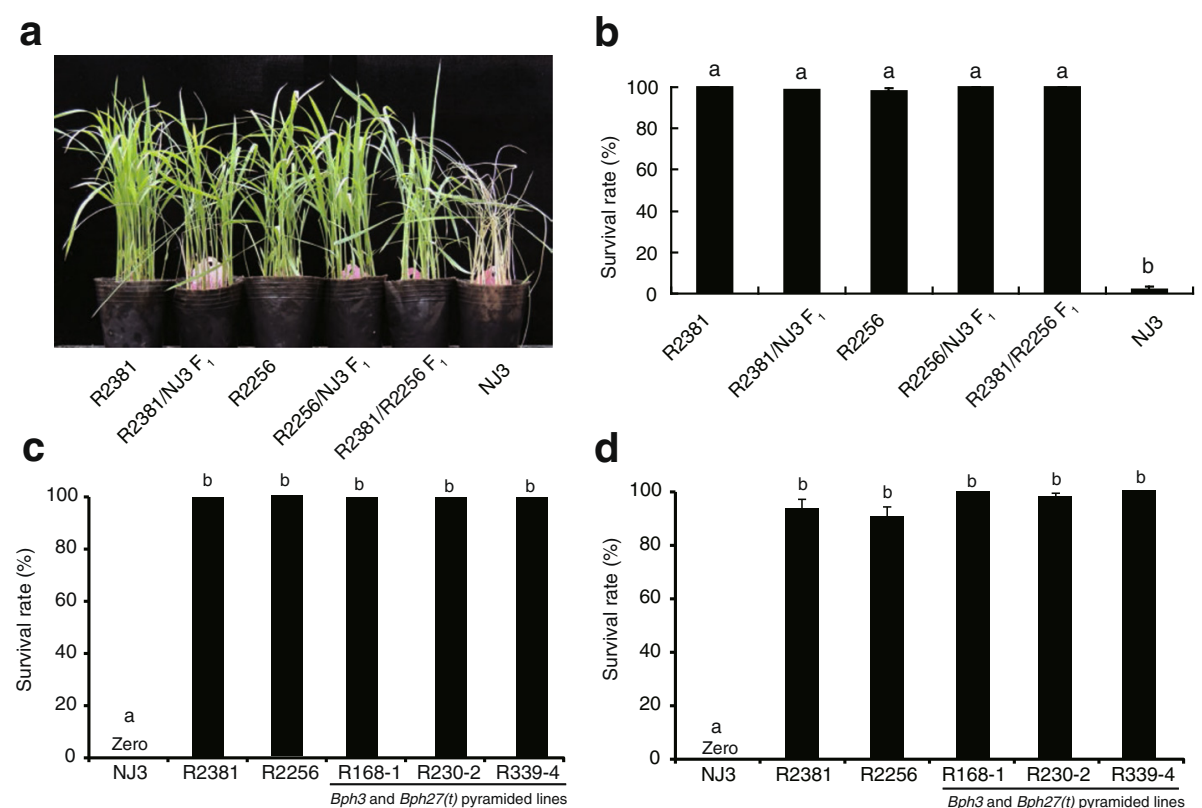

d

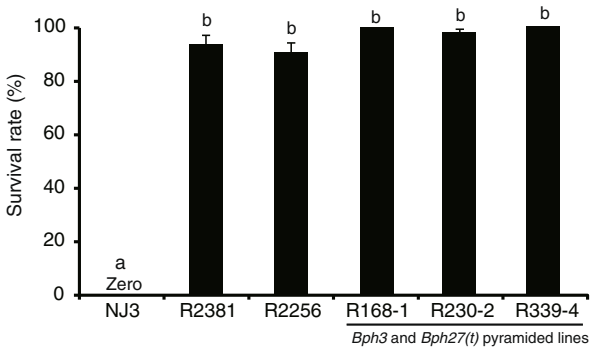

Fig. $3 \mathrm{BPH}$ resistance of Bph3 and Bph27(t) homogenous and heterozygous genotypes (a and $\mathbf{b}$ ), and two gene pyramided lines at seedling stage one-week and 3-weeks after infested with BPH (c and $\mathbf{d}$ ). Letters indicate a significant difference at $P<0.01$ by the Student's $t$-test

The plants were harvested after ripening and the yield components including number of effective panicle and grains per panicle, seed setting rate and 1000-grain weight were examined (Table 2). Compared with controls, seed setting rate and 1000-grain weight of NJ3 infested with $\mathrm{BPH}$ were significantly reduced in both seasons. In contrast, the above components of introgression lines containing either $B p h 27(t)$ or $B p h 3$ were rarely influenced by $\mathrm{BPH}$ (Table 2). Upon infestation with $\mathrm{BPH}$ in 2014, the actual yield of NJ3 and 93-11 were reduced by $34.9 \%$ and $43.6 \%$, respectively, but BPH caused little damage on R2381, R2256 and R3-166 (Fig. 4). Therefore, introducing $B p h 27(t)$ could significantly improve the $\mathrm{BPH}$ resistance and reduced the yield losses caused by $\mathrm{BPH}$.

\section{Pyramiding of Bph3 and Bph27(t)}

To pyramid the two $\mathrm{BPH}$ resistance genes and develop more durable $\mathrm{BPH}$ resistance rice, the plants with the two $\mathrm{BPH}$ resistance genes were screened from $\mathrm{F}_{2}$ population derived from R2381/R2256 $\mathrm{F}_{1}$, then Bph3 and $B p h 27(t)$ pyramided lines were selected. Among them, eight lines with both homologous Bph3 and Bph27(t) were subsequently evaluated for the $\mathrm{BPH}$ resistance. NJ3 were completely dead about 7 days after infestation with $\mathrm{BPH}$, all three lines with zero mortality rate displayed high $\mathrm{BPH}$ resistance (Fig. 3c). When about 3-weeks after infestation, the survival rate of R2381 and R2256 arrived at about $5.1 \%$ and $7.3 \%$, respectively, but the pyramided lines also showed invisible damaged symptom (Fig. 3d).
These results indicate that $B p h 3$ and $B p h 27(t)$ pyramided lines showed higher resistance than single gene introgression lines.

\section{Discussion}

Resistant cultivars with single resistance gene are currently hampered by the rapid breakdown of $\mathrm{BPH}$ resistance (Cohen et al. 1997; Alam and Cohen 1998). Thus, there is an urgent need to use more effective $\mathrm{BPH}$ resistance genes or pyramiding different resistance genes to develop more durable resistant rice cultivars. For example, Bph14 and Bph15 pyramided lines showed higher resistance than Bph14 or Bph15 single introgression lines ( $\mathrm{Hu}$ et al. 2012). Pyramiding Bph6 and Bph12 line also showed significant additive effect against BPH compared with introgression of single gene (Qiu et al. 2012). These studies prove that pyramiding two or more $\mathrm{BPH}$ resistant genes is an efficient strategy to develop higher and durable $\mathrm{BPH}$ resistance cultivars (Chen et al. 2000; $\mathrm{Tu}$ et al. 2000; Hittalmani et al. 2000). Compared with previous used genes, such as Bph1 and Bph2, Bph3 performs more broad spectrum and durable resistance (Cruz et al. 2011). Bph27(t) is also a high $\mathrm{BPH}$ resistance gene. The pyramiding of $B p h 3$ and $B p h 27(t)$ will provide more useful material for breeding durable $\mathrm{BPH}$ resistant cultivars. Bph3 and Bph27(t) were linked on rice chromosome 4, moreover, $\mathrm{RH}$ and $\mathrm{Ba}$ the two donor parents come from Sri Lanka, the Indel markers used for selection of $B p h 3$ and $B p h 27(t)$ showed nonpolymorphic between $\mathrm{RH}$ and $\mathrm{Ba}$, so it is difficult to 
Table 2 Comparison analysis of the damage caused by BPH on recurrent parent and introgression lines

\begin{tabular}{|c|c|c|c|c|c|c|c|c|c|c|c|}
\hline \multirow[t]{2}{*}{ Lines } & \multicolumn{6}{|l|}{2013} & \multicolumn{5}{|l|}{2014} \\
\hline & & EPP & GPP & SSR (\%) & TGW (g) & TYP (g) & EPP & GPP & SSR (\%) & TGW (g) & $\operatorname{TYP}(\mathrm{g})$ \\
\hline \multirow[t]{2}{*}{ NJ3 } & $\begin{array}{l}\text { Non- } \\
\text { infested }\end{array}$ & $\begin{array}{l}10.07 \pm \\
0.06\end{array}$ & $\begin{array}{l}101.92 \pm \\
1.17\end{array}$ & $95.67 \pm 0.46$ & $24.15 \pm 0.07$ & $23.72 \pm 0.27$ & $\begin{array}{l}10.03 \pm \\
0.02\end{array}$ & $\begin{array}{l}101.23 \pm \\
1.21\end{array}$ & $96.12 \pm 0.22$ & $24.27 \pm 0.1$ & $23.69 \pm 0.89$ \\
\hline & Infested & $\begin{array}{l}10.07 \pm \\
0.07\end{array}$ & $\begin{array}{l}102.14 \pm \\
1.23\end{array}$ & $\begin{array}{l}87.67 \pm \\
1.61^{* *}\end{array}$ & $\begin{array}{l}21.04 \pm \\
0.23^{* *}\end{array}$ & $\begin{array}{l}18.97 \pm \\
0.28^{* *}\end{array}$ & $\begin{array}{l}10.03 \pm \\
0.09\end{array}$ & $\begin{array}{l}104.38 \pm \\
0.83\end{array}$ & $\begin{array}{l}65.23 \pm \\
1.74^{* *}\end{array}$ & $\begin{array}{l}20.16 \pm \\
0.33^{* *}\end{array}$ & $\begin{array}{l}13.77 \pm \\
0.67^{* *}\end{array}$ \\
\hline \multirow[t]{2}{*}{ R2381 } & $\begin{array}{l}\text { Non- } \\
\text { infested }\end{array}$ & $\begin{array}{l}9.85 \pm \\
0.15\end{array}$ & $\begin{array}{l}99.27 \pm \\
1.03\end{array}$ & $92.54 \pm 0.15$ & $24.14 \pm 0.24$ & $21.84 \pm 0.22$ & $\begin{array}{l}9.91 \pm \\
0.05\end{array}$ & $\begin{array}{l}98.21 \pm \\
0.98\end{array}$ & $92.54 \pm 0.15$ & $24.23 \pm 0.11$ & $21.82 \pm 0.32$ \\
\hline & Infested & $\begin{array}{l}9.79 \pm \\
0.15\end{array}$ & $\begin{array}{l}102.83 \pm \\
5.92\end{array}$ & $88.59 \pm 1.52$ & $23.65 \pm 0.25$ & $21.09 \pm 0.21$ & $\begin{array}{l}9.89 \pm \\
0.16\end{array}$ & $\begin{array}{l}101.36 \pm \\
4.63\end{array}$ & $89.13 \pm 2.24$ & $22.88 \pm 0.52$ & $20.44 \pm 1.89$ \\
\hline \multirow[t]{2}{*}{ R2256 } & $\begin{array}{l}\text { Non- } \\
\text { infested }\end{array}$ & $\begin{array}{l}9.85 \pm \\
0.08\end{array}$ & $\begin{array}{l}101.97 \pm \\
2.04\end{array}$ & $90.94 \pm 1.82$ & $24.72 \pm 0.16$ & $22.08 \pm 0.23$ & $\begin{array}{l}10.05 \pm \\
0.05\end{array}$ & $\begin{array}{l}92.68 \pm \\
1.96\end{array}$ & $93.01 \pm 2.02$ & $24.52 \pm 0.13$ & $21.24 \pm 0.97$ \\
\hline & Infested & $\begin{array}{l}10.31 \pm \\
0.21\end{array}$ & $\begin{array}{l}102.83 \pm \\
5.82\end{array}$ & $\begin{array}{l}86.72 \pm \\
0.37^{*}\end{array}$ & $23.18 \pm 0.26$ & $21.08 \pm 0.11$ & $\begin{array}{l}10.11 \pm \\
0.19\end{array}$ & $94.96 \pm 3.1$ & $89.1 \pm 1.87^{*}$ & $23.62 \pm 0.14$ & $20.2 \pm 1.12$ \\
\hline
\end{tabular}

Number of effective panicle per plant (EPP), Number of grains per panicle (GPP), Seed setting rate (SSR), 1000-Grain Weight (TGW) and Theoretical yield per plant (TYP) of NJ3, R2381 and R2256 were measured under normal and BPH-infested conditions $\left({ }^{*} P<0.05, *{ }^{*} P<0.01\right)$

distinguish the two genes in the process of pyramiding the two genes. In order to pyramid Bph3 and Bph27(t), single-gene introgression lines without each other locus were developed firstly, then, the two resistance genes were pyramided by intercrossing with these single-gene introgressed lines through MAS into commercial japonica rice cultivar. The two genes pyramided lines displayed higher resistance than those lines with single resistance gene. The development of two genes pyramided lines provides innovative resources for breeding of durable BPH-resistant rice cultivars

The $\mathrm{BPH}$ resistance level of heterozygous genotype is important for hybrid improvement. Some BPH genes display partial dominant resistance, and their heterozygotes show moderately resistance or even susceptible to $\mathrm{BPH}$. If these genes will be integrated in hybrid improvement, they have to be separately introgressed into two parent cultivars to guarantee the resulting hybrids carry multiple and complementary resistance genes. Hybrids

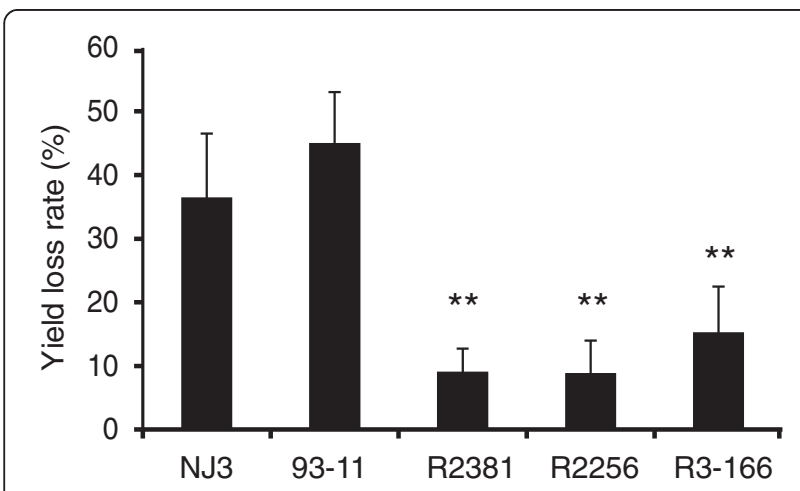

Fig. 4 Actual yield loss rate of NJ3, 93-11, R2381, R2256 and R3-166 under $\mathrm{BPH}$-infested conditions. Error bars indicate s.e.m. of the mean by the Student's t-test (** $P<0.01)$ between Bph3 or Bph27(t) introgression lines and NJ3 showed similar BPH resistance with homologous Bph3 or $B p h 27(t)$ introgressed lines. In accordance with previous studies (Lakshminarayana and Khush 1977; Ikeda and Kaneda 1981; Nemoto et al. 1989), these results indicate both genes are dominant BPH resistance genes. This made them great potential in future hybrid improvement.

'Linkage Drag' is a common phenomenon in disease and insect resistance breeding program (Lewis et al. 2007; Liu et al. 2009; Young and Tanksley 1989). RH and $\mathrm{Ba}$ the two donor parents are Sri Lanka landrace varieties, exhibited large genetic divergence with japonica rice cultivars. After six times backcross with NJ3, we also found the partial anthers indehiscence of single gene introgression lines resulted in the reduction of spikelet fertility compared with that of NJ3 under BPH non-infestation condition (Table 2). We detected the genetic background of the japonica ingression line and found that a large fragment of chromosome 4 from $\mathrm{Ba}$ was introduced into the recipient parent (Fig. 2). Previously several sterile loci in indica-japonica cross were found on the short arm of chromosome 4, such as $S 9$ and $S 28$ (Sobrizal et al. 2002; Zhao et al. 2006). We speculated the lower spikelet fertility may be caused by these sterile loci. In order to break the linkage drag, we tried to continuously backcross with NJ3. Unexpectedly, our efforts failed due to serious segregation distortion. The break of linkage drag would depend on a larger population in the future study.

Previous studies usually introgressed BPH resistance genes into indica rice cultivars. However, BPH has rose up as major destructive insect throughout Japonica varieties grown area. The absence of BPH resistance Japonica cultivars will put rice production in danger. In present study, we successfully introduce $B p h 27(t)$ into commercial Japonica variety $\mathrm{N} 33$ based on MAS, furtherly pyramided Bph27(t) with Bph3 in Japonica 
variety. These introgression lines can act as excellent 'base materials' and will have wide applications in breeding durable $\mathrm{BPH}$ resistant varieties.

\section{Conclusions}

We introgressed single or two BPH resistance genes into two elite rice cultivars using MAS. The introgression of $\mathrm{BPH}$ resistance genes significantly improved the $\mathrm{BPH}$ resistance level and reduced the yield loss caused by BPH. The development of BPH resistance lines has a promising future in molecular breeding of durable $\mathrm{BPH}$-resistant rice cultivars.

\section{Methods}

\section{Plant materials and BPH population}

Balamawee (Ba) with Bph27(t) were used as $\mathrm{BPH}-$ resistant donor parent. Japonica cultivar (cv.) Ningjing3 (NJ3) and indica cultivar (cv.) 93-11 were used as recurrent parent. R2381, a Bph3-carrying line was selected from a $\mathrm{BC}_{6} \mathrm{~F}_{2}$ population by backcross between donor parent RH and recurrent parent NJ3 (Liu et al. 2015). $\mathrm{BPH}$ population was originally collected from rice fields in Nanjing, China and maintained on TN1 plant under greenhouse condition at Nanjing Agricultural University.

\section{Evaluation of BPH resistance}

A seedling bulk test was conducted to study plant reaction to BPH feeding according to the standard evaluation systems of IRRI with minor modifications (IRRI, 1988). To ensure all seedlings were at the same growth stage for BPH infestation, seeds were pre-germinated. About 30 seeds from individual plant were sown in a $10 \mathrm{~cm}$-diameter plastic pot with a hole at the bottom. Seven days after sowing, seedlings were thinned to 25 plants per pot. At the second-leaf stage, the seedlings were infested with 2 nd to 3 rd instar BPH nymphs at 10 insects per seedling. When all the TN1 plants were dead, the seedling mortality of other cultivars or lines was recorded. Three replicates were used for each cultivar or line.

For evaluation of $\mathrm{BPH}$ resistance in the field, in the summer of 2013 and 2014 at Nanjing, the introgression lines and recurrent parents were alternatively grown in a sealed field with Nylon net with three replicate plots at a spacing of $16.7 \mathrm{~cm} \times 20 \mathrm{~cm}$. Each plot consisted of 10 rows with 10 plants per row. About $100 \mathrm{BPHs}$ per plant were infested at the booting stage. Another three replicate plots were cultivated in other field as the controls. Water and fertilizer were managed regularly. Ten individuals were taken for measurements of agronomic traits, including productive panicles per plant, total grains per panicle, seed setting rate, and 1000-grain weight. In 2014, the actual yield of each plots were measured and the yield loss rate were calculated by the following formula:
Yield loss rate $(\%)=1$ - Yield under BPH infestation condition/Yield under normal condition

\section{DNA extraction and non-denaturing PAGE}

Plant DNA was extracted from fresh rice leaves using the CTAB method (Murray and Thomson 1980). The extracted DNA was dissolved in TE buffer for further analysis. Amplified products were separated in $8 \%$ nondenaturing PAGE and visualized with silver staining (Sanguinetti et al. 1994).

\section{Introgression of $B p h 27(t)$ and pyramiding $B p h 27(t)$ and Bph3 through MAS}

The procedure of introgression and pyramiding Bph27(t) and $B p h 3$ was as described in Additional file 1: Figure S1. To introgress Bph27(t) to Japonica cultivar NJ3, we firstly crossed $\mathrm{Ba}$ with $\mathrm{NJ} 3$ and got hybrid $\mathrm{F}_{1}$, then, $\mathrm{F}_{1}$ was continuously backcrossed with NJ3 for 6 times. In each generation, two Indel markers Q52 and Q31 were used to select positive progenies. $\mathrm{BC}_{6} \mathrm{~F}_{1}$ were selfcrossed to produce $\mathrm{BC}_{6} \mathrm{~F}_{2}$. The homozygous plants at $B p h 27(t)$ in $\mathrm{BC}_{6} \mathrm{~F}_{2}$ were selected. Meanwhile, the same procedure was conducted to introgress $B p h 27(t)$ to indica cultivar 93-11, except that markers were replaced by RM471 and Q58 (Table 1).

Then, Bph27(t) and Bph3 introgressed Japonica lines R2256 and R2381 were crossed to pyramid the two BPH resistance genes.

\section{Additional file}

Additional file 1: Figure S1. The procedure of introgression and pyramiding Bph27(t) and Bph3. (PDF $338 \mathrm{~kb}$ )

\section{Competing interests}

The authors declare that they have no competing interests.

\section{Authors' contributions}

YL, HD, HK, GP carried out the molecular marker-assisted selection. JH, GP and $\mathrm{JH}$ participated in the evaluation of $\mathrm{BPH}$ resistance at seedling stage, and $L C, Z Q, J H$ and $X C$ carried out the evaluation of $B P H$ resistance in the field. $\amalg$ performed the statistical analysis. $L L$ and $Y C$ helped to improve the manuscript. YQL participated in the design of this study and helped to draft and improve the manuscript. JW made the overall design of this study. All authors read and approved the final manuscript.

\section{Acknowledgements}

This work was supported by NSFC (31522039, 31471470), Natural Science Foundation of Jiangsu Province of China (BK20150026), Jiangsu 333 Program (BRA2012126), National Key Transformation Program (2014ZX08001-001), the Jiangsu Agricultural Scientific Self-innovation Fund (No.CX[14]2030), Key research and development project of Jiangsu Province (BE2015363).

Received: 10 November 2015 Accepted: 29 April 2016

Published online: 31 May 2016

\section{References}

Akhtar S, Bhat MA, Wani SA, Bhat KA, Mir S, Chalkoo MR, Wani SA (2010) Marker assisted selection in rice. J Phytol 2:66-81 
Alam SN, Cohen MB (1998) Durability of brown planthopper, Nilaparvata lugens, resistance in rice variety IR64 in greenhouse selection studies. Entomol Exp Appl 89:71-78

Chen S, Lin XH, Xu CG, Zhang QF (2000) Improvement of bacterial blight resistance of 'Minghui 63', an elite restorer line of hybrid rice, by molecular marker-assisted selection. Crop Sci 40:239-244

Cheng XY, Zhu LL, He GC (2013) Towards understanding of molecular interactions between rice and the brown planthopper. Mol Plant 6:621-634

Cohen MB, Alam SN, Medina EB, Bernal CC (1997) Brown planthopper, Nilaparvata lugens, resistance in rice cultivar IR64: mechanism and role in successful $N$. lugens management in Central Luzon, Philippines. Entomol Exp Appl 85:221-229

Cruz PA, Arida A, Heong KL, Horgan FG (2011) Aspects of brown planthopper adaptation to resistant rice varieties with the Bph3 gene. Entomol Exp Appl 141:245-257

He J, Liu YQ, Liu YL, Jiang L, Wu H, Kang HY, Liu SJ, Chen LM, Liu X, Cheng XN, Wan JM (2013) High-resolution mapping of brown planthopper (BPH) resistance gene Bph27(t) in rice (Oryza sativa L.). Mol Breeding 31:549-557

Heinrichs EA, Mochida O (1984) From secondary to major pest status: the case of insecticide-induced rice brown planthopper, Nilaparvata lugens, resurgence. Protect Ecol 7:201-218

Hittalmani S, Parco A, Mew TV, Zeigler RS, Huang N (2000) Fine mapping and DNA marker-assisted pyramiding of the three major genes for blast resistance in rice. Theor Appl Genet 100:1121-1128

Hu G, Lu F, Zhai BP, Lu MH, Liu WC, Zhu F, Wu XW, Chen GH, Zhang XX (2014) Outbreaks of the Brown Planthopper Nilaparvata lugens (Stål) in the Yangtze River Delta: Immigration or Local Reproduction? PLoS One 9:e88973

Hu J, Li X, Wu CJ, Yang CJ, Hua HX, Gao GJ, Xiao JH, He YQ (2012) Pyramiding and evaluation of the brown planthopper resistance genes Bph14 and Bph15 in hybrid rice. Mol Breeding 29:61-69

Huang D, Qiu Y, Zhang Y, Huang F, Meng J, Wei S, Li R, Chen B (2013) Fine mapping and characterization of $\mathrm{BPH} 27$, a brown planthopper resistance gene from wild rice (Oryza rufipogon Griff.). Theor Appl Genet 126:219-229

Ikeda R, Kaneda C (1981) Genetic analysis of resistance to brown planthopper, Nilaparvata lugens Stål, in rice. Jpn J Breed 31(3):279-285

IRRI (1988) Standard evaluation systems for rice. IRRI, Manila, Philippines

Jena KK, Kim SM (2010) Current status of brown planthopper (BPH) resistance and genetics. Rice 3:161-171

Khush GS (1977) Breeding for resistance in rice. New York Acad Sci 287:296-308

Khush GS, Virk PS (2005) IRRI varieties and their impact. International Rice Research Institute. Los Baños, Philippines, International Rice Research Institute

Lakshminarayana A, Khush GS (1977) New genes for resistance to the brown planthopper in rice. Crop Sci 17:96-100

Lewis R, Linger L, Wolff M, Wernsman E (2007) The negative influence of N-mediated TMV resistance on yield in tobacco: linkage drag versus pleiotropy. Theor Appl Genet 115:169-178

Liu WQ, Fan YY, Chen J, Shi YF, Wu JL (2009) Avoidance of Linkage Drag Between Blast Resistance Gene and the QTL Conditioning Spikelet Fertility Based on Genotype Selection Against Heading Date in Rice. Rice Sci 16:21-26

Liu YQ, Wu H, Chen H, Liu YL, He J, Kang HY, Sun ZG, Pan G, Wang Q, Hu JL, Zhou F, Zhou KN, Zheng XM, Ren YL, Chen LM, Wang YH, Zhao ZG, Lin QB, Wu FQ, Zhang X, Guo XP, Cheng XN, Jiang L, Wu CY, Wang HY, Wan JM (2015) A gene cluster encoding lectin receptor kinases confers broad-spectrum and durable insect resistance in rice. Nat Biotechnol 33(3):301-305

Murata K, Fujiwara M, Murai H, Takumi S, Mori N, Nakamura C (2000) Bph9, a dominant brown planthopper resistance gene, is located on the long arm of rice chromosome 12. Rice Genet Newsl 17:84-86

Murray MG, Thomson WF (1980) Rapid isolation of high molecular weight plant DNA. Nucleic Acid Res 8:4321-4325

Nemoto H, Ikeda R, Kaneda C (1989) New genes for resistance to brown planthopper, Nilaparvata lugens Stål, in rice. Jpn J Breed 39:23-28

Qiu YF, Guo JP, Jing SG, Zhu LL, He GC (2010) High-resolution mapping of the brown planthopper resistance gene Bph6 in rice and characterizing its resistance in the 9311 and Nipponbare near isogenic backgrounds. Theor Appl Genet 121:1601-1611

Qiu YF, Guo JP, Jing SG, Zhu LL, He GC (2012) Development and haracterization of japonica rice lines carrying the brown planthopper-resistance genes Bph12 and Bph6. Theor Appl Genet 124:485-494

Sanguinetti CJ, Dias NE, Simpson AJG (1994) Rapid silver staining and recovery of PCR products separated on polyacrylamide gels. Biotechniques 17:915-919
Sobrizal Y, Matsuzaki A, Yoshimura A (2002) Mapping of pollen semi-sterility gene, S28 (t), on rice chromosome 4. Rice Genet Newslett 19:80-82

Su CC, Zhai HQ, Wang CM, Sun LH, Wan JM (2006) SSR mapping of brown planthopper resistance gene Bph9 in Kaharamana, an indica rice (Oryza sativa L.). Acta Genet Sin 33:262-268

Suh JP, Yang SJ, Jeung JU, Pamplona A, Kim JJ, Lee JH, Hong HC, Yang Cl, Kim YG, Jena KK (2011) Development of elite breeding lines conferring Bph18 gene-derived resistance to brown planthopper (BPH) by marker-assisted selection and genome-wide background analysis in japonica rice (Oryza sativa L.). Field Crops Res 120:215-222

Tanaka K, Endo S, Kazano H (2000) Toxicity of insecticides to predators of rice planthoppers: Spiders, the mirid bug and the dryinid wasp. Appl Entomol Zool 35:177-187

Tu JM, Zhang GA, Datta K, Xu CG, He YQ, Zhang QF, Khush GS, Datta SK (2000) Field performance of transgenic elite commercial hybrid rice expressing Bacillus thuringiensis $\delta$-endotoxin. Nat Biotechnol 18:1101-1104

Way MJ, Heong KL (1994) The role of biodiversity in the dynamics and management of insect pests of tropical irrigated rice-a review. B Entomol Res 84:567-587

Wu H, Liu YQ, He J, Liu YL, Jiang L, Liu LL, Wang CM, Cheng XN, Wan JM (2014) Fine mapping of brown planthopper (Nilaparvata lugens Stål) resistance gene Bph28(t) in rice (Oryza sativa L.). Mol Breeding 33:909-918

Young N, Tanksley S (1989) RFLP analysis of the size of chromosomal segments retained around the Tm-2 locus of tomato during backcross breeding. Theor Appl Genet 77:353-359

Zhao ZG, Wang CM, Jiang L, Zhu SS, Ikehashi H, Wan JM (2006) Identification of a new hybrid sterility gene in rice (Oryza sativa L.). Euphytica 151:331-337

Zhai BP (2011) Rice planthoppers: a China problem under the international perspectives. Chin J Appl Entomol 48:1184-1193

\section{Submit your manuscript to a SpringerOpen ${ }^{\circ}$ journal and benefit from:}

- Convenient online submission

- Rigorous peer review

- Immediate publication on acceptance

- Open access: articles freely available online

- High visibility within the field

- Retaining the copyright to your article

Submit your next manuscript at $\boldsymbol{s p r i n g e r o p e n . c o m ~}$ 